\title{
Classification of Partial Discharges
}

\author{
F. H. Kreuger, E. Gulski and A. Krivda \\ Delft University of Technology, \\ Electrical Engineering Department, Delft, \\ The Netherlands
}

\begin{abstract}
Classification of partial discharges aims at the recognition of discharges of unknown origin. This classification is vital for the evaluation of discharges in tested constructions. For a long time, classification was performed by eye, studying discharge patterns at the well-known ellipse at an oscilloscope screen. In later years the introduction of digital processing techniques allowed automation of the recognition procedure. This paper reports on these procedures and applies them to a number of actual HV constructions which suffered from partial discharges. The results of these tests showed that a quite satisfactory recognition of discharges took place.
\end{abstract}

\section{INTRODUCTION}

$\mathrm{W}$ HEN dealing with partial discharges (PD) at least three stages of information handling are needed to collect sufficient data for an evaluation. These stages are: detection, classification and location.

Detection is usually performed with a classical discharge detector having a bandwidth of $\sim 250 \mathrm{kHz}$. These detectors are commercially available or can easily be built and belong to the standard equipment of $\mathrm{HV}$ laboratories. Discharge detection is performed sometimes by acoustical or optical means, but these methods are not studied in this paper although the authors are convinced that equally good results can be obtained [1]. In this first stage, electrical detection shows the presence and the magnitude of the PD under observations, but nothing more.

Classification aims at recognizing the defect causing the discharges, such as internal or surface discharges, corona, treeing, etc. This information is vital for estimating the harmfulness of the discharge.

Location aims at locating the position of the discharge in a dielectric construction. In an ideal case, this position reveals the type of material or the interface between materials and the local field strength where the discharge takes place, which is also vital information for the assessment of the risks involved.

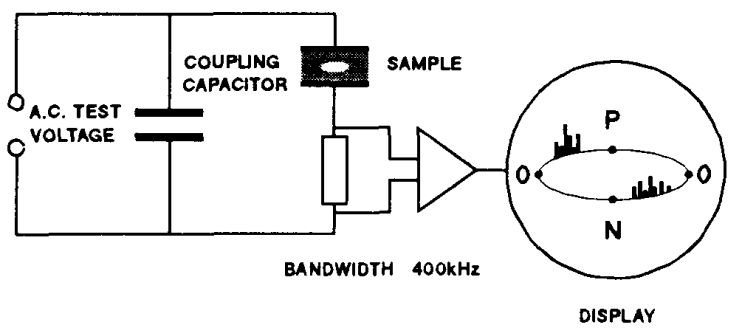

Figure 1.

Classic discharge detection. The pulses caused by the discharges in the sample are displayed on an elliptical timebase, where 0 coincides with the zero points, $\mathrm{P}$ with the positive crest and $\mathrm{N}$ with the negative crest of the ac test voltage.

All three stages are needed for evaluation, which in turn leads to decision making like rejection, remaking, repair of equipment, etc. This paper deals only with classification, based on electrical detection.

\section{RECOGNITION}

Classification is based on recognition. There are two basic possibilities for recognizing discharges: phase related and time resolved recognition.

$0018-9367 / 93 / \$ 3.00$ (C) 1993 IEEE 


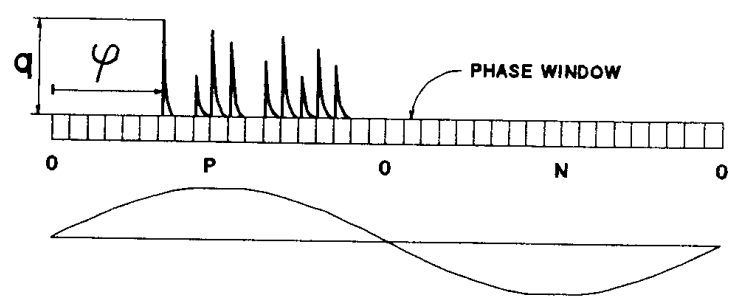

Figure 2.

Each impulse on the display in Figure 1 is specified by its magnitude $q$ and its phase angle $\varphi$. The resulting pattern of all impulses is characteristic for the type of discharge.

\subsection{PHASE RELATED RECOGNITION}

This method uses the classic discharge detector and studies the patterns which occur in the 50 or $60 \mathrm{~Hz}$ sinewave, see Figure 1. These patterns are familiar to us in the shape of the widely used ellipse on a 50 or $60 \mathrm{~Hz}$ time base. Each discharge pulse in the pattern reflects the physical process at the discharge site and a strong relationship has been found between the shape of these patterns and the type of defect causing them. Phase related recognition offers a number of advantages, especially for use at industrial components [2].

The method is independent of the electrical path between defect and detector. As long as the detection circuit reveals the phase angle and the relative height of the impulses it does not matter whether a discharge signal comes from a complicated set of transformer windings or from a simple capacitor: the characteristics $\varphi$ and $q$ in Figure 2 are of interest only.

Moreover, for the same reason this method is independent of the type of detector or its coupling circuit. The shape of the single pulses is not relevant, only their relative height and phase angle. The only requirement is on the detector resolution, which should be in the order of $\sim 1 \mu$ s.

Phase related recognition makes use of classic discharge detectors which are standard equipment in a $\mathrm{HV}$ laboratory. Equipment for recognition is added to the detector and does not replace it.

\subsection{TIME RESOLVED RECOGNITION}

In recent years very interesting results have been obtained with time resolved detection, using detection circuits with bandwidths of $\sim 500$ to $1000 \mathrm{MHz}$. In Figure $3(\mathrm{a})$ simplified version of such a circuit is shown. In

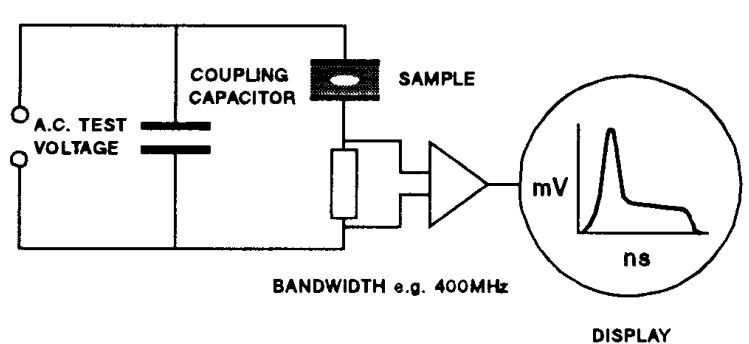

Figure 3.

The same basic circuit as in Figure 1, but with a time constant in the order of $\sim 3$ ns and a $\sim$ $500 \mathrm{MHz}$ bandwidth. The impulses are displayed at a triggered timebase and reveal the true shape of the partial discharge current in the defect.

this circuit the true shape of the charge displacement in the defect, e.g. a cavity, is shown at a nanosecond scale. From these shapes far-reaching conclusions can be drawn on the physical state of the discharge site, on the type of the gaseous discharge and even on the aging process which takes place in or at the dielectric. The method has some distinct differences with phase related recognition. A disadvantage is that the vhf detection circuits are not easy to use in industrial test sites, although for GIS [3, 4] and for $\mathrm{HV}$ cables $[3,5]$ good circuits for industrial use have been realized.

Furthermore, pulse distortion in the path between defect and detector affects the information. Samples with complicated circuits such as power transformers are less suited for this method [3].

The time resolved method, however, has attractive advantages. There is a direct relationship between the physics in the defect and the shape of the signal. It also has been found that stages in the aging of dielectric materials can be recognized with this method: it has been shown in [6] that the time-resolved shape of the discharge impulse changes distinctively with the aging process in a cavity. In many cases external noise is less cumbersome at these very high frequencies than in the frequency bands of classical detectors.

Time resolved recognition will not be discussed further in this paper, but it has been mentioned here because much progress is made in this field and, moreover, combined use of phase-related and time-resolved methods is under development as shown for instance in [7].

\section{PHASE RELATED RECOGNITION}

Phase related recognition consists in general of three stages as shown in Figure 4. The procedure is preceded 


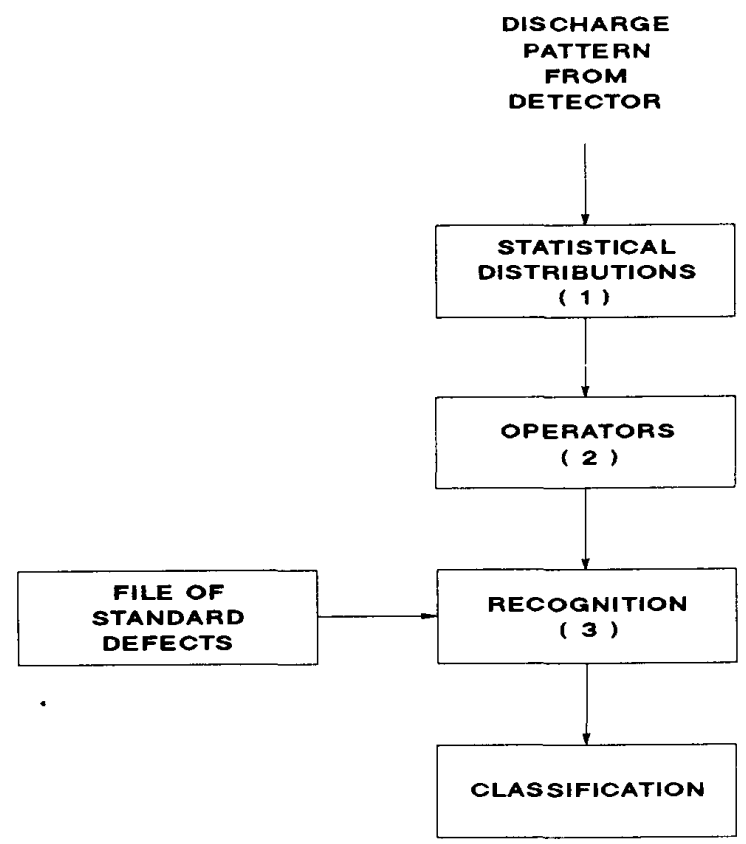

Figure 4.

Phase related recognition in three stages: in stage 1 statistical distributions are derived from the discharge pattern of Figure 2. In stage 2 several operators are applied to these distributions to describe their characteristic shape. In stage 3 the results of a set of operators is compared to those of known discharges in a file; if this set coincides with a set of known discharges, recognition takes place and the unknown discharge is classified.

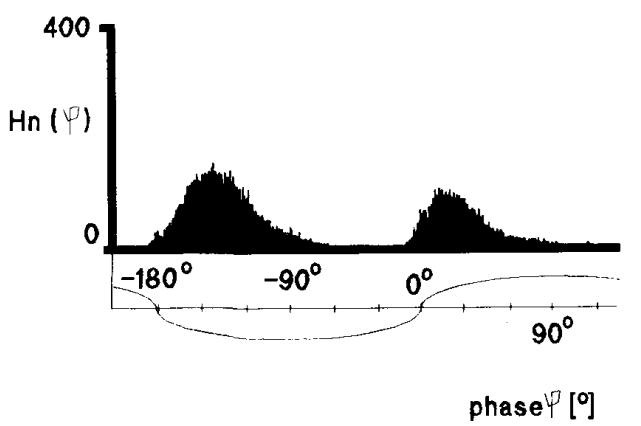

Figure 5.

Distribution of the number of discharges in each phase window of the 50 or $60 \mathrm{~Hz}$ time base. This example reflects surface discharges in air.

by classic detection as in Figure 1, and it must be emphasized that that part of the measurement must be well executed, using all available experience in this field: the data handling following it is not meant for suppression of disturbances or correcting measuring errors. The first

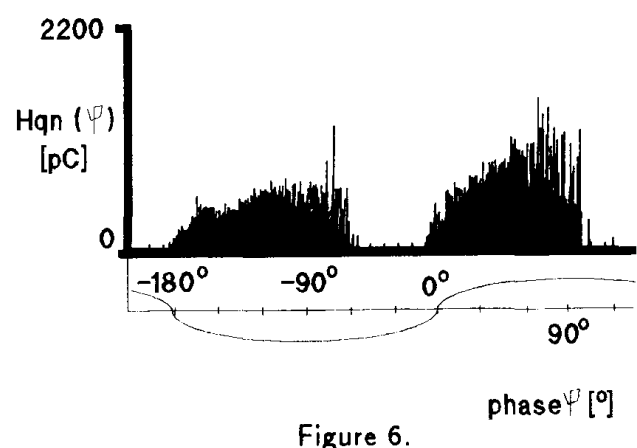

Distributions of the magnitude of discharges in each phase window, again for surface discharges in air.

stage in Figure 4 consists of making a distribution of the discharge patterns that arrive from the classical detector. The sinewave ( 50 or $60 \mathrm{~Hz}$ ) of Figure 2 is divided in a number of phase windows (either 4000 or 3333 ), and usually two distributions are determined: the first gives the number of discharge impulses in each phase window, see the example of Figure 5, and the second one observes the average magnitude of the discharge impulses as a function of the phase angle, see Figure 6. Many other distributions could be made, but these two have given sufficiently good results to date.

These distributions have characteristic shapes which vary with the type of the defect [8]. Experience has shown that the shape belonging to the positive half of the HV sine wave differs much from that of the negative half, so that in fact four distributions, and their characteristic shapes are available for recognition purposes.

In theory, the shapes of these distributions can be used for classifying discharges, either by recognizing them by eye $[3]$ or by observing them with neural networks $[9,10]$. However, a more distinctive method has been based on the application of operators [11] and represents stage (2) of the procedure shown in Figure 4. The term 'operator' is used in this paper to denote mathematical descriptions or parameters, this is in accordance with the growing practice in this field of pattern recognition, where such parameters as skewness, kurtosis, crosscorrelation factor, etc. are called operators $[8,11,12]$. In this approach several aspects of the shape of the distributions are described by mathematical functions as shown below. The first operator is skewness,

$$
S_{k}=\frac{\sum\left(x_{i}-\mu\right)^{3} \cdot p_{i}}{\sigma^{3}}
$$

where $x_{i}$ is the recorded value and $p_{i}$ the probability of frequency of appearance for that value $\boldsymbol{x}_{i}$ in time window 

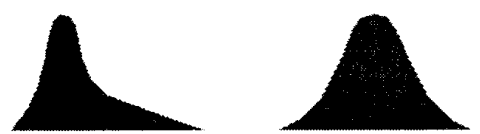

$S k=p o s$

Sk $=0$
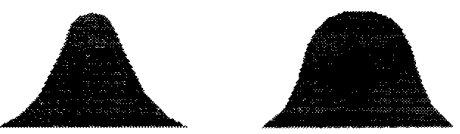

$\mathrm{Ku}=\mathrm{pos}$

$\mathrm{Ku}=0$

$\mathrm{Ku}=\mathrm{neg}$

Figure 7.

Examples of shapes of distributions and their resulting operators.

$i, \mu$ is the mean value $\sum x_{i} \cdot p_{i}$, and $\sigma$ is the variance $\sigma^{2}=\sum\left(x_{i}-\mu\right)^{2} \cdot p_{i}$

The skewness represents the asymmetry of the distribution. If the distribution is symmetric, $S_{k}=0$, if it is asymmetric to the left, $S_{k}>0$, and if asymmetric to the right, $S_{k}<0$, see Figure 7 . The kurtosis is defined as

$$
K_{u}=\frac{\sum\left(x_{i}-\mu\right)^{4} \cdot p_{i}}{\sigma^{4}}-3
$$

representing the sharpness of the distribution. If the distribution has the same sharpness as a normal distribution, $K_{u}=0$. If it is sharper than normal, $K_{u}>0$, and if it is flatter, $K_{u}<0$, see Figure 7 .

The number of peaks ?? $P_{e}$, is defined by the number of local tops in the distribution, and a local top is defined as

$$
\begin{aligned}
& \frac{d y_{i-1}}{d x_{i-1}}>0 \\
& \frac{d y_{i+1}}{d x_{i+1}}>0
\end{aligned}
$$

where the $d y_{i \pm 1} / d x_{i \pm 1}$ is the differential coefficient before and after the possible local top of the distribution. In actual cases, one to ten peaks have been distinguished.

The cross correlation factor

$$
c c=\frac{\sum x_{i} y_{i}-\sum x_{i} \sum y_{i} / n}{\sqrt{\left[\sum x_{i}^{2}-\left(\sum x_{i}\right)^{2} / n\right]\left[\sum y_{i}^{2}-\left(\sum y_{i}\right)^{2} / n\right]}}
$$

where $x_{i}$ is the mean discharge magnitude in window $i$ of the positive half cycle and $y_{i}$ the mean discharge magnitude in the corresponding window in the negative half cycle; $n$ is the number of phase windows per half cycle.

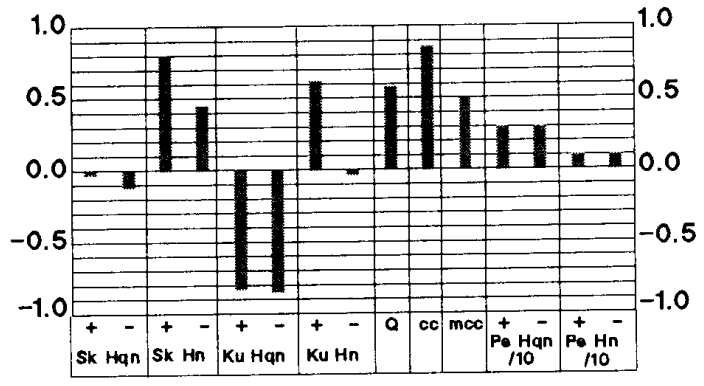

Figure 8.

Results of a set of operators obtained from the surface discharge in air of Figures 5 and 6.

The crosscorrelation factor indicates the difference in shape of the distributions in the positive and negative half cycle. If the shapes are the same (but not necessarily of equal height) $c c=1$, if they differ completely, $c c=0$.

The discharge factor is

$$
Q=\frac{Q_{s}^{-} / N^{-}}{Q_{s}^{+} / N^{+}}
$$

where $Q_{s}^{+}$and $Q_{s}^{-}$are the sum of discharges of the mean pulse height distribution in the positive and the negative half of the voltage cycle; $N^{+}$and $N^{-}$are the number of discharges of the mean pulse height distribution in the positive and the negative half of the voltage cycle. The discharge factor $Q$ describes the difference in the mean discharge level in the negative and positive distributions. $Q=1$ means equal discharge levels, $Q=0$ means a large difference.

The modified cross correlation factor is

$$
m c c=Q \cdot c c
$$

which thus equals the product of $Q$ and $c c$.

These operators are applied to the four distributions mentioned above and result after calculation in a set of fifteen numbers, one number for each measure. This can be displayed graphically, as shown in Figure 8 for the example of a surface discharges in air. Such a set of numbers serves now as a fingerprint of a certain defect.

Again, such a fingerprint could be compared by eye to the other prints in order to characterize a discharge, but it has been found useful to automate this part of the recognition procedure as well.

This recognition procedure represents stage (3) of the procedures as shown in Figure 4. Each time a defect has been characterized by the operators, its fingerprint 


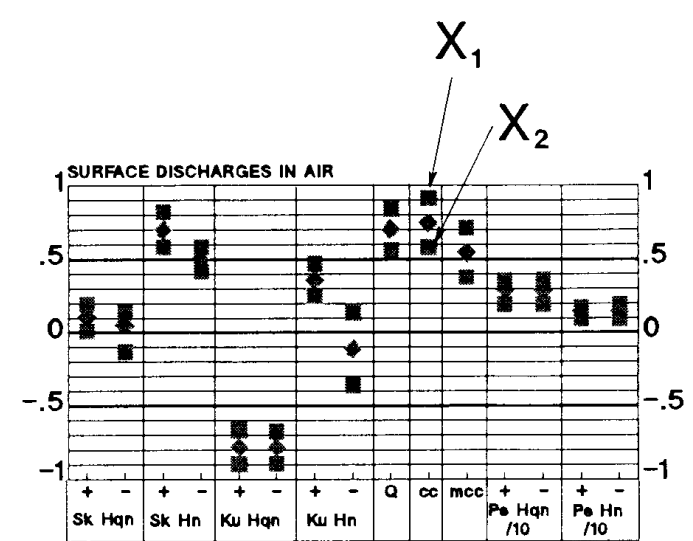

Figure 9 ,

Average fingerprint of many tests on surface discharges in air. The most probable value of each operator varies between the limits $X_{1}$ and $X_{2}$. If the operator of an unknown discharge falls within these limits it is recognized as belonging to the characteristics of a surface discharge and is scored as a hit in the recognition procedure.

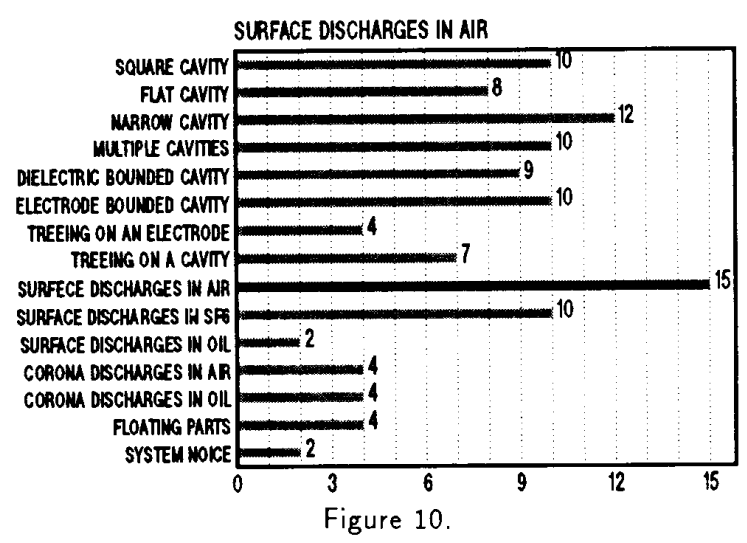

Recognition rate: the number of hits for an unknown defect is counted for each standard defect in the file, the highest score classifies the unknown defect. In this example the surface discharge of the Figures 1 to 3 is shown.

is compared with a file of standard defects. This defect may be recognized to resemble one of the standard defect results, as schematically indicated in Figure 4. For this recognition procedure two characteristics have been developed, the recognition rate [12] and the centour score [14].

The recognition rate is determined as follows. Several samples of a known defect (or standard defect, see Section 4.1) are taken and measured for discharges. For each function the mean of the measured values is determined, and the standard deviation is derived from the scatter of

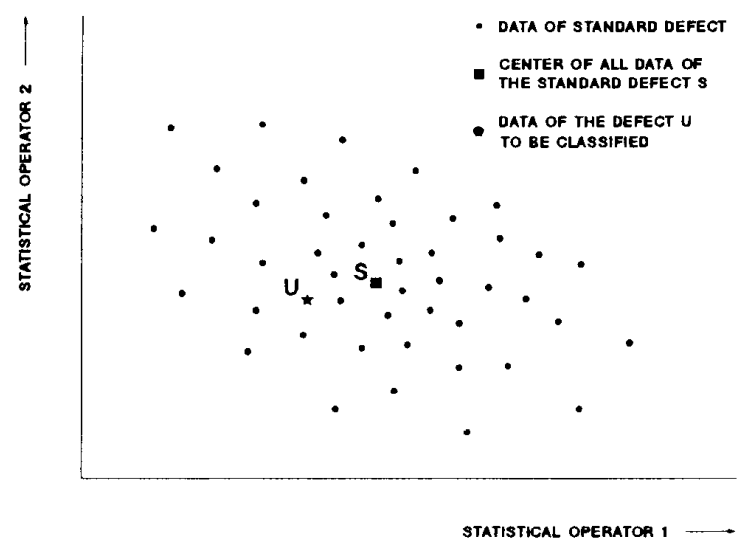

Figure 11.

For the centour score procedure, the measured values of the operators belong to a certain $\mathrm{PD}$ are displayed in a multidimensional space. In this example a two-dimensional version is shown. The results of many tests on a standard defect are shown as dots, the mathematical center of these dots is indicated by $S$. The centour score of an unknown defect $U$ is classified by the percentage of dots (of the known defect) which are further removed from the center than $U$.

these values. In this way a representative picture can be drawn as shown in Figure 9, each operator having a most probable value between two limits $X_{1}$ and $X_{2}$ :

$$
\begin{aligned}
& X_{1}=M_{s o}-\frac{t \cdot s}{\sqrt{N}} \\
& X_{2}=M_{s o}+\frac{t \cdot s}{\sqrt{N}}
\end{aligned}
$$

where $M_{s o}$ is the arithmetic mean of values of the statistical operator obtained from a series of $N$ observations of one and the same type defect, $s$ is the standard deviation of this series and $t$ is a statistical test parameter depending on $N$. Such average fingerprint can be made of many standards, or otherwise known defects. The procedure is now as follows: an unknown defect is measured and the value of each operator is compared to that of the known defect. If the difference is small, a hit is recorded. In this way all fifteen operators are compared and the number of results that coincide is recorded; this number is called recognition rate. The recognition rate can vary between fifteen, when all operators coincide, and zero when none fall within the limits of the standard deviation. The procedure is repeated, so that an unknown defect is compared with many known or standard defects, and the best fit is deemed to represent the cause of the unknown defect, see Figure 10. The recognition rate is described in more detail in [12].

The other procedure, centour score, is defined as fol- 
lows. The operators of a standard defect are displayed in an $k$-dimensional space. In Figure 11 a two-dimensional example of such a display is shown, where one result is represented by one plot. Again, a number of samples of a known defect is measured and each of the results is displayed, see Figure 11, so that a collection of dots occurs. The mathematical center of these dots is determined and the position of an unknown discharge can be compared with this center. The centour score is now defined as the percentile rank of the data (dots) that are further away from the center of the known discharge population than the measured value. In the simple two-dimensional example of Figure 11 the results of the unknown defect $U$ are compared to the scattered data of a standard defect with center $S$. The centour score of the unknown defect is now $80 \%$ if eighty percent of the dots of the standard defect are further away from center $S$ than $U$ itself.

The centour score can vary in this way from 0 to $100 \%$. This percentage is not the same as the probability that $U$ is identical to the standard defect $S$, but it gives us the best possible reflection of it. The results of a classification of an unknown defect by centour score are given as a list, for instance like that in Table 1 . The centour score is described in more detail in Appendix A.

Table 1.

Example of a centour scores of an unknown defect, shown as a table. In this case the unknown defect appears to resemble surface discharges in air with $99 \%$

\begin{tabular}{|l|c|}
\hline \hline \multicolumn{2}{|c|}{ Centour score } \\
\hline Surface discharges in air & $99 \%$ \\
Narrow cavity & $15 \%$ \\
Surface discharges in $\mathrm{SF}_{6}$ & $3 \%$ \\
\hline
\end{tabular}

\section{MODELS}

So far, only mathematical methods have been studied. However, a classification of this type can be successful only if based on a sound physical base. For this reason a philosophy has been developed on the type of physical models that are needed when classifying unknown discharges. Three levels of models have been developed.

(1) Standard defects. These are simple two-electrode models, representing the physical shape of possible defects in dielectrics. At this level the relationship to actual $\mathrm{HV}$ constructions is small. Examples are shown in Figure 12 , where different types of artificial defects in synthetic dielectrics are represented [12].

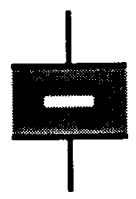

FLAT-DIEL

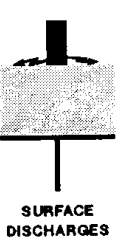

ISCHARGES

IN NR, ON

(n)

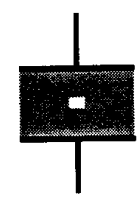

SQUARE-DIEL

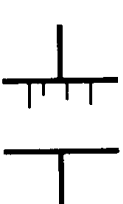

CORONA IN

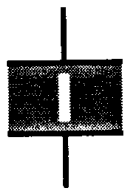

SHANP-DIEL

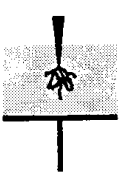

TREEING

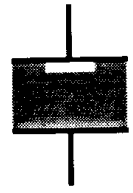

FUT-COND

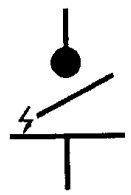

FLATING PART
Figure 12.

Standard defects, tested to create a database for recognition of discharges.

(2) Industrial models. These are models of industrial defects, either downscaled or at full scale. Artificial defects are made in these models, such as cavities in a cable model, or artificial conductive particles in a GIS compartment. These models come as near to actual cases as they can be made, but it has to be kept in mind that actual defects in industrial objects may differ from these artificial ones; think of the smoothness of the walls of an extrusion-processed cavity, or the complicated structure of a natural particle in GIS.

(3) Industrial objects. Recognizing defects in actual industrial objects is the final goal and therefore the categories as developed under (1) and (2) must be tested in actual industrial objects. This task requires many years of practical experience in the test departments of manufacturers, similar to the twentyfive or more years of experience with the present visual techniques. However, some promising results with actual objects and semiproducts have been obtained already in the laboratory and will be reported here.

Another use that can be made of this classification technique is the comparison of industrial products among themselves. Every manufacturer encounters sometimes a production failure where samples are rejected for too high discharge levels. After improvement of the production procedure the products pass the final tests; but if some years later another case of rejection comes up it will be extremely useful to compare the characteristics of this new problem with the results of earlier ones.

Before dealing with the acquired experience two questions have to be answered first. Is it necessary to know the details of the physical processes in the defect under survey? The answer is no. Although much is known of 
the processes in cavity discharges, corona, treeing, etc. [6], this knowledge has not been introduced in the algorithms and experience has taught that satisfactory recognition results can be obtained without it.

Can this recognition technique also be used for monitoring? The answer is: probably yes, but much has yet to be done to give this technique a firm base. Monitoring seems to be a more remote goal. The examples in this paper are based on laboratory results, and no on-line tests have been undertaken to date.

\subsection{STANDARD DEFECTS}

In order to acquire a database of known defects, 13 types of standard defects were simulated in simple physical models. For each defect several identical models were built and these were analyzed in order to obtain a statistically based data set for each defect: 10 to 15 analyzes per defect were made. These artificial defects were:

1. FLAT-DIEL. A cavity made by punching a hole in a stack of dielectric sheets, see Figure 12. The diameter is larger than the height. The cavity is surrounded by dielectric on all sides, the dimensions are $5 \mathrm{~mm}$ diameter, $1 \mathrm{~mm}$ height.

2. EXTRA-FLAT-DIEL sized $10 \mathrm{~mm}$ diameter, $1 \mathrm{~mm}$ height.

3. SQUARE-DIEL. A cavity made in the same way and also surrounded by dielectric, but with a diameter as large as its height, $1 \mathrm{~mm}$ diameter, $1 \mathrm{~mm}$ height.

4. SHARP-DIEL. Similar, but the height of the cavity is far larger than its diameter, $1 \times 5 \mathrm{~mm}$.

5. FLAT-COND. A flat cavity, as in case 2, but one side is bounded by the conductor.

6. MULT-DIEL. A number of spherical cavities in a polyethylene slab, surrounded by the dielectric and ranging from 0.5 to $4 \mathrm{~mm}$ diameter.

7. SUR-AIR. Surface discharges in ambient air on a Perspex ${ }^{\text {TM }}$ slab as shown in Figure 12.

8. SUR-SF 6 . Surface discharges in 1 atm $\mathrm{SF}_{6}$, in the same configuration as case 7 .

9. SUR-OIL. Surface discharges in transformer oil, in the same configuration as case 7 .
10. COR-AIR. Corona discharges at a single point or multiple points in ambient air, as shown in Figure 12.

11. COR-OIL. Corona discharges in transformer oil in a single point configuration as in Figure 12.

12. TREE-COND. Treeing initiated by a sharp conductor $(40,50$ or $100 \mu \mathrm{m}$ point diameter) in Perspex, measured after an initiation period of $\sim 1 \mathrm{~h}$.

13. FLOA-PART. A floating particle was imitated by a configuration as shown in Figure 12. A floating metallic plate picks up some voltage from the $\mathrm{HV}$ source and sparks over a 1 to $2 \mathrm{~mm}$ gap to the ground electrode.

All these models were tested and data acquisition took place during a twenty minute period at HV. The voltage was generally raised to 20 to $60 \%$ over inception voltage, with the exception of the treeing models where lower voltages were required to prevent untimely breakdown.

\subsubsection{SELF RECOGNITION}

First it was investigated whether the analyzing system could distinguish one type of defect from the others by feeding the average value of the operators of one defect to the system. It was then checked whether the average result of that defect was recognized and also whether it was sufficiently distinguished from the other standard defects. The results are shown in Table 2 . The recognition rate is given as the number of operators that coincide with those of the model. The maximum rate is fifteen; rates going down to eleven are shown. The centour score is given in percent. The maximum obtainable value is $99 \%$, all values above $10 \%$ are shown.

The resulting classifications are marked by ++ if the recognition is clear and by + if positive information has been given. The results marked by $\circ$ are commented in the two remarks below.

From this Table it can be concluded that the standard defects built into the artificial models are well recognized by the system. Two remarks have to be made:

1. The analyzer has apparently also second and third thoughts: the recognition rate gives several extra answers at levels below the maximum of fifteen. The centour score gives also some extra answers at levels below the maximum of $99 \%$. 
Table 2. The results of the self recognition of studied standard defects. Details in text.

\begin{tabular}{|c|c|c|c|c|c|c|c|}
\hline \hline & Defect & \multicolumn{2}{|c|}{ Recognition rate } & Verdict & \multicolumn{2}{|c|}{ Centour score } & Verdict \\
\hline 1 & Flat-Diel & Flat-Diel & 15 & ++ & Flat-Diel & $99 \%$ & ++ \\
& & Extra-Flat-Diel & 14 & + & Extra-Flat-Diel & $47 \%$ & + \\
& & Flat-Cond & 12 & 0 & Flat-Cond & $26 \%$ & \\
\hline 2 & Extra-Flat-Diel & Extra-Flat-Diel & 15 & ++ & Extra-Flat-Diel & $99 \%$ & ++ \\
& & Flat-Cond & 11 & & Flat-Cond & $60 \%$ & 0 \\
& & Flat-Diel & 11 & & & & \\
\hline 3 & Square-Diel & Square-Diel & 15 & ++ & Square-Diel & $99 \%$ & ++ \\
& & Flat-Diel & 12 & 0 & Flat-Diel & $64 \%$ & 0 \\
& & Mult-Diel & 12 & & Flat-Cond & $45 \%$ & \\
\hline 5 & Flat-Cond & Flat-Cond & 15 & ++ & Flat-Cond & $99 \%$ & ++ \\
& & Mult-Diel & 11 & & Flat-Diel & $52 \%$ & 0 \\
& & & & & Square-Diel & $25 \%$ & \\
\hline 6 & Mult-Diel & Mult-Diel & 15 & ++ & Mult-Diel & $99 \%$ & ++ \\
& & Others & $\leqslant 11$ & & Flat-Cond & $25 \%$ & \\
\hline 7 & Sur-Air & Sur-Air & 15 & ++ & Sur-Air & $99 \%$ & ++ \\
& & Sharp-Diel & 12 & 0 & Extra-Flat-Diel & $32 \%$ & 0 \\
& & & & & Tree-Cond & $29 \%$ & 0 \\
\hline 9 & Sur-Oil & Sur-Oil & 15 & ++ & Sur-Oil & $99 \%$ & ++ \\
& & Others & $\leqslant 9$ & & Tree-Cond & $73 \%$ & \\
\hline 10 & Cor-Äir & Cor-Air & 15 & ++ & Cor-Air & $99 \%$ & ++ \\
& & Sharp-Diel & 11 & & Others & $0 \%$ & \\
\hline 12 & Tree-Cond & Tree-Cond & 15 & ++ & Tree-Cond & $99 \%$ & ++ \\
& & Others & $\leqslant 11$ & & & & \\
\hline
\end{tabular}

2. Some confusion can be expected, when distinguishing between dielectric-bounded and conductor-bounded cavities, as follows from the extra answers in cases 1,2 , 3,5 and also in recognizing square cavities, see case 3 .

An anomaly was found in case 9 , surface discharges in oil, where a large content of treeing was found; it was, however, not certain whether tracking or treeing had been developed during the comparatively long period of testing.

A general conclusion can be drawn on the interpretation of these extra answers. This conclusion will be used in the next Section and is described as follows. The recognition rates that are 'three or more numbers below the maximum score' do not count any more and are discarded. The centour scores that fall 'below half the maximum score' do not count and also are discarded.

\subsection{INDUSTRIAL MODELS AND OBJECTS}

Tests on industrial models (artificial defects in industrial objects) and on industrial objects (natural defects in industrial objects) are discussed here in one section as in this stage of the work the differences between them were relatively small. Six different objects were used, leading to ten tests at natural defects and six tests at artificial defects. The samples and their treatment (if any) are described here.

Each sample was tested during 3 to $20 \mathrm{~min}$, which proved to be ample time for collecting the statistical data. The test voltage was usually 20 to $60 \%$ over the discharge inception voltage.

\subsubsection{BUSHING-TRANSFORMER (A)}

This is a $10 \mathrm{kV}$ bushing with builtin windings for current measuring, according to Figure 13. This apparatus consists of an epoxy resin insulator, current-measuring windings and a grounded casing. The cross section of the bushing is shown in Figure 13. In this Figure the critical sites where discharges can occur are shown. First, the metal casing that makes contact with the epoxy resin insulator may cause surface discharges, see discharge sites (a). Secondly, the conducting layer on the insulator can adhere badly to the epoxy resin resulting in a flat cavity, see discharge sites (b). 


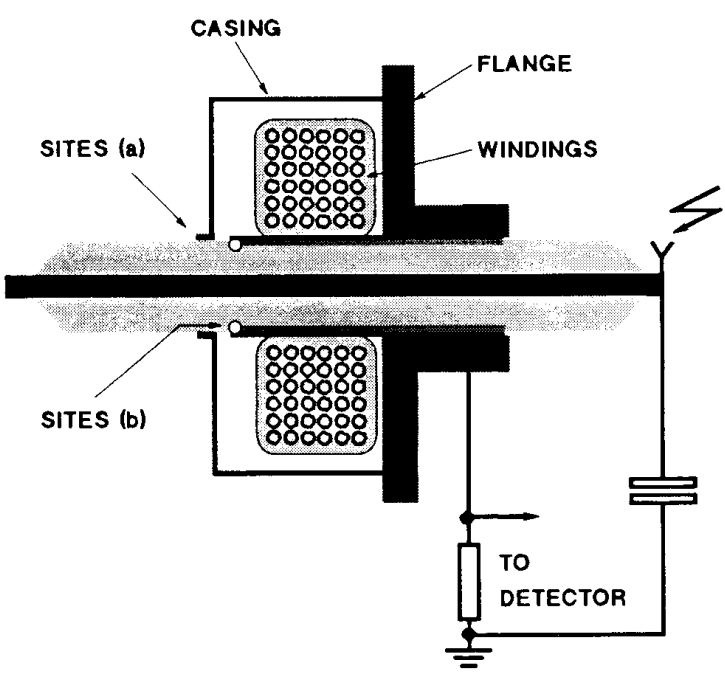

Figure 13.

Bushing transformer, tested for discharges with and without casing.

\subsubsection{BUSHING-TRANSFORMER (B)}

The same bushing after removal of the casing. In this case internal discharges might be expected.

Testing gave the following answers for case A, see Table 3. From the recognition rate it was concluded that surface and internal discharges were present, in accordance with expectation. The centour score showed a very low answer, thus giving no classification.

Table 3.

The recognition rate and centour score for bushing transformer $(\mathrm{A})$.

\begin{tabular}{|c|c|c|c|}
\hline \hline Recognition rate & \multicolumn{2}{|c|}{ Centour score } \\
\hline Sur-Air & 11 & Extra-Flat-Diel & $4 \%$ \\
Flat-Diel & 10 & & \\
Other Cavities & $8-9$ & & \\
\hline \hline
\end{tabular}

Case B was characterized by results shown in Table 4: Both were interpreted as fairly flat cavities. The surface discharges had apparently disappeared by taking off the casing, in accordance with expectation.

\subsubsection{CURRENT TRANSFORMER}

This is a $50 \mathrm{kV}$ current transformer which showed discharges below operating voltage, caused by short-circuit
Table 4.

The recognition rate and centour score for bushing transformer (B).

\begin{tabular}{|c|c|c|c|}
\hline \hline Recognition rate & \multicolumn{2}{|c|}{ Centour score } \\
\hline Flat-Cond & 11 & Extra-Flat-Diel & $26 \%$ \\
Extra-Flat-Diel & 10 & Flat-Diel & $13 \%$ \\
Other Cavities & 9 & & \\
\hline \hline
\end{tabular}

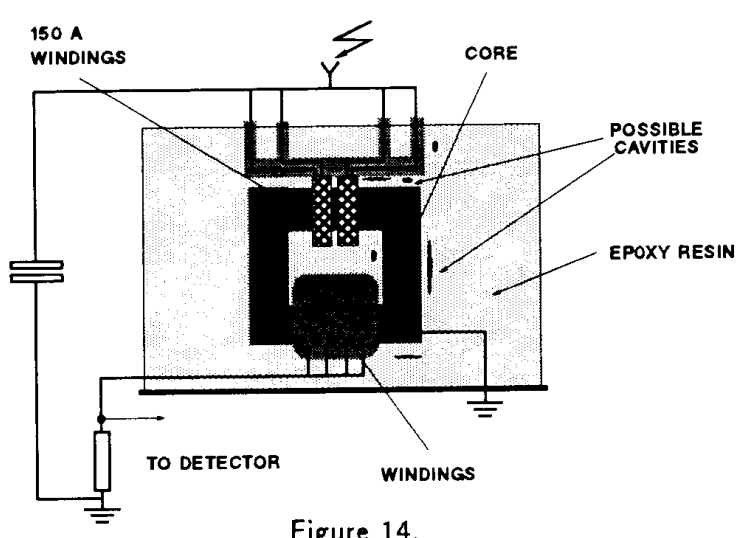

Figure 14.

Current transformer for $50 \mathrm{kV}$ network tested for discharges after a short circuit.

testing. Cavities are expected in the insulation between the current winding and core, see Figure 14. After testing for discharges the following recognition rates were found, see Table 5, which result was interpreted as a cavity, probably flat, which agrees with expectation. The centour score gave no indication.

Table 5.

The recognition rate and centour score for $50 \mathrm{kV}$ current transformer. The centour score gave no indication.

\begin{tabular}{|c|c|c|c|}
\hline \hline \multicolumn{2}{|c|}{ Recognition rate } & \multicolumn{2}{|c|}{ Centour score } \\
\hline Extra-Flat-Diel & 9 & All & $<1 \%$ \\
Sharp-Diel & 7 & & \\
Others & $\leqslant 6$ & & \\
\hline
\end{tabular}

\subsubsection{BELTED CABLE (PHASE R)}

To analyze the discharges in a three-phase configuration, a three-core belted-type cable rated for $10 \mathrm{kV}$ was tested. Because the electric field in a three-phase constructions rotates, and the shape of the field changes continuously, discharge detection is more difficult than 


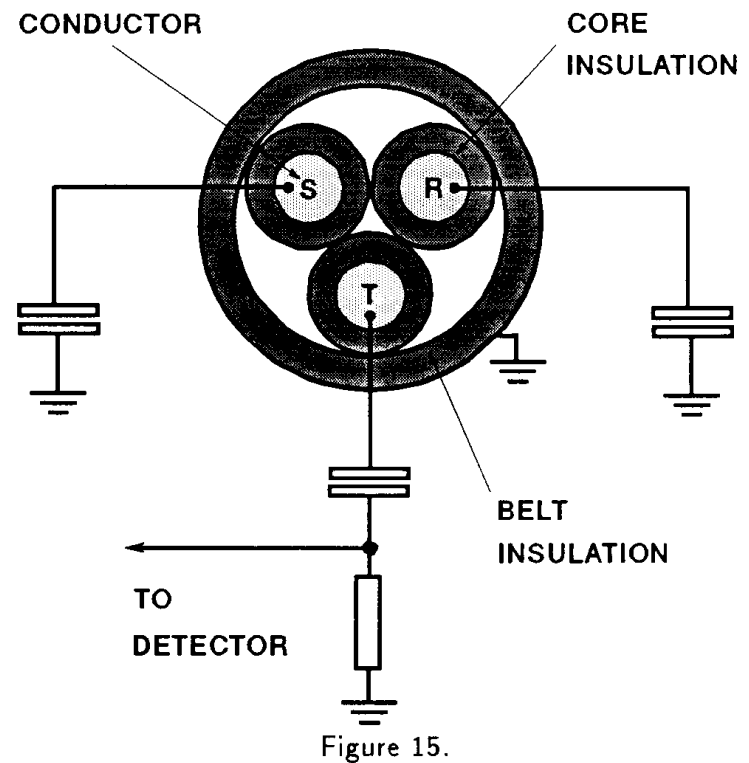

Cross section of a three-core belted cable, tested for discharges at three-phase voltage.

in single phase constructions. In practice, discharges can well be located in one of the cores [13]. It is known that the partial discharges in this type of cable occur in air gaps between the cores in the center of the cable or at the 'corners' between a core and the belt insulation, see Figure 15.

The investigations were carried out on an aged $6.5 \mathrm{~m}$ long cable with discharge free terminations under oil. The cable was energized at three-phase voltage. In Figure 15 the schematic cross section of this cable as well as the measuring setup are shown.

\subsubsection{BELTED CABLE (PHASE S AND T).}

The results of phase $\mathrm{R}$ were quite confusing, see Table 6 , which was interpreted as giving no classification in both cases. The recognition rates of phases $\mathrm{S}$ and $\mathrm{T}$ gave rates at level 4 or 5 ; which was interpreted as no classification. The centour score of phase $\mathrm{S}$ was TREEING = $16 \%$ and that of phase $\mathrm{T}$ for all defects $\leq 1 \%$, which were interpreted as no classification.

In all these cases it was deemed to be correct that no classification could be made: the standard defects to be compared were of an entirely different construction and they were not measured at three-phase voltage either.
Table 6 .

The recognition rate and centour score for threephase belted $P E$ cable (core R).

\begin{tabular}{|c|c|c|c|}
\hline \hline Recognition rate & \multicolumn{2}{|c|}{ Centour score } \\
\hline Extra-Flat-Diel & 10 & Flat-Con & $14 \%$ \\
Flat-Con & 9 & & \\
Square-Diel & 8 & & \\
\hline
\end{tabular}

4.2.6 BUSHING (A AND B)

This is a $150 \mathrm{kV}$ bushing of the well-known capacitor graded type, with oil impregnated paper insulation. The bushing was rejected from service because of discharges at a voltage below operating voltage (bushing $\mathrm{A}$ ).

The bushing above was much improved by applying a $500 \mathrm{kPa}$ oil pressure to the system. After removal of this oil pressure, the inception voltage was permanently increased to a safe value above operating voltage. A discharge analysis was then made at a slightly higher voltage under the heading bushing $B$.

Test (A) gave the following recognition rates, see Table 7 .

Table 7.

The recognition rate and centour score for $150 \mathrm{kV}$ bushing (A).

\begin{tabular}{|c|c|c|c|}
\hline \hline \multicolumn{2}{|c|}{ Recognition rate } & \multicolumn{2}{|c|}{ Centour score } \\
\hline Flat-Cond & 12 & Flat-Diel & $3 \%$ \\
Extra-Flat-Diel & 11 & & \\
Flat-Diel & 10 & & \\
Others & $\leqslant 7$ & & \\
\hline
\end{tabular}

This was interpreted as flat cavities, without concluding to electrode bounded or dielectric cavities (uncertainty in making this distinction was expected when discussing the results of standard defects in Section 4.1.1). Ultrasonic detection confirmed this and revealed that discharges were located inside the body of the bushing. The centour score was $3 \%$ for FLAT-DIEL, which was accepted as no classification.

Test (B) gave confusing results for the recognition rate and clear results for the centour score, see Table 8.

The recognition rate was interpreted as cavities in general without classifying the type of cavity. It was regarded as no classification. The centour score was interpreted 
Table 8.

The recognition rate and centour score for $150 \mathrm{kV}$ bushing (B).

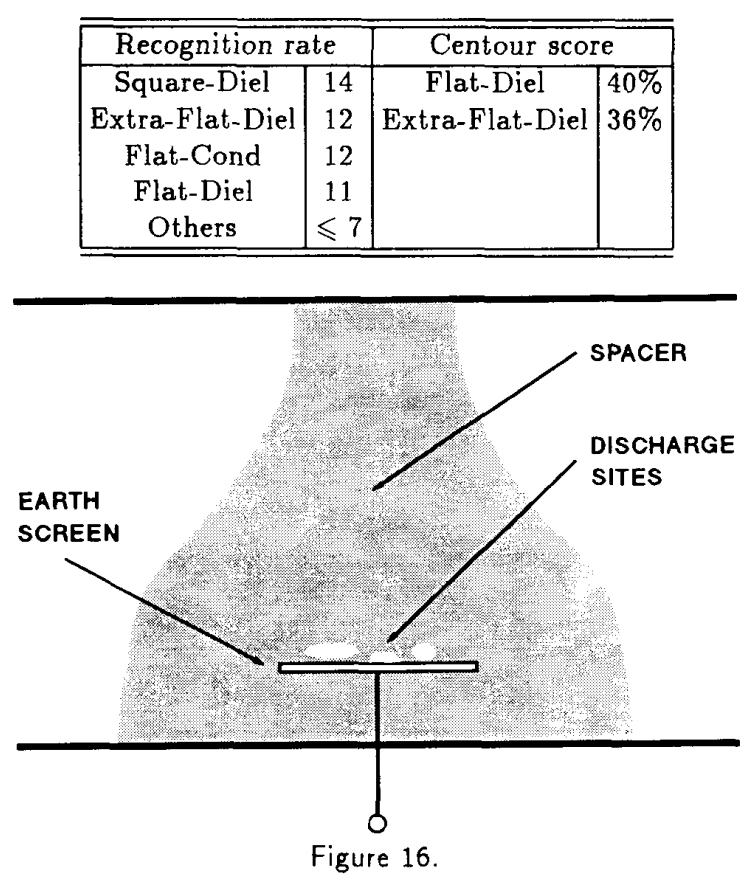

Spacer in $400 \mathrm{kV}$ GIS with faulty ground screen. Discharges which occur at the screen are analyzed.

as flat cavities, which could be well in accordance with reality.

\subsubsection{GIS-SPACER}

The test was made in a $400 \mathrm{kV}$ GIS compartment at $500 \mathrm{kPa} \mathrm{SF}$, were a grounded screen inside a spacer was connected to the detector. This screen was made of copper mesh and it was known that that this mesh did not well adhere to the epoxy resin of the spacer, see Figure 16. Classification was as well made to compare the spacer with standard defects as to compare it to similar spacers measured before (called CAV-SPAC). The results are shown in Table 9 . It was concluded from the recognition rate that the spacer had internal discharges similar to other spacers of the same type, vaguely resembling cavity discharges of other origin. The centour score indicated clearly a spacer cavity. The second and third answers were less than half the maximum score and were thus discarded.
Table 9.

The recognition rate and centour score for measurement carried out on spacer in a $400 \mathrm{kV}$ GIS compartment at $500 \mathrm{kPa} \mathrm{SF}_{6}$.

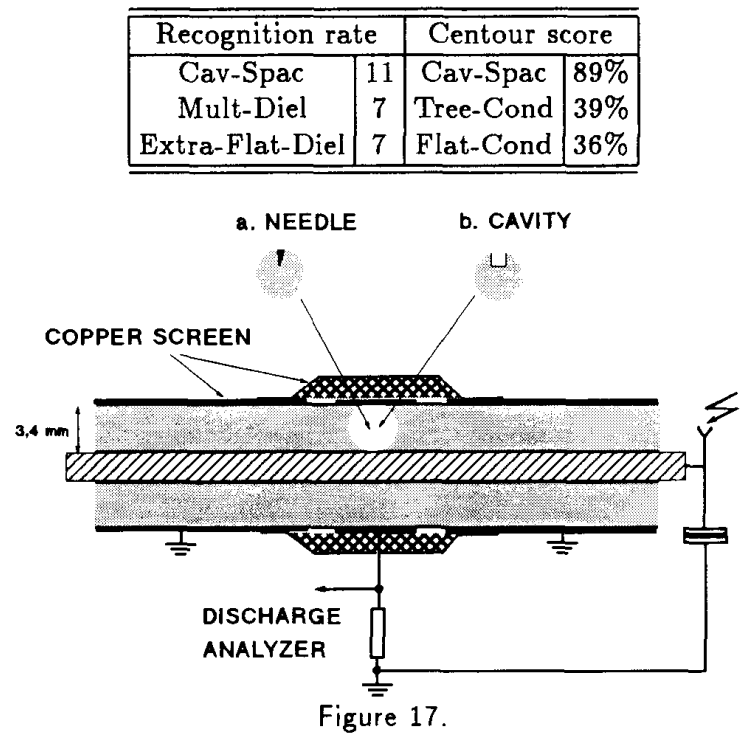

$10 \mathrm{kV}$ polyethylene cable with either artificial treeing (a) or artificial cavity (b).

\subsubsection{SPRING IN GIS}

During installation of a compartment in $400 \mathrm{kV}$ GIS a metal spring from the conductor system was lost and dropped to the bottom of the compartment, where it formed a 'floating part'. The discharge pattern of this situation could be compared to FLOA-AIR, the representation of a floating part in air in the list of standard defects. Moreover, this situation could easily be simulated in a GIS compartment (FLOA-SF 6 ) and the actual discharges could be compared to this one. The results are shown in Table 10. It was concluded that this pattern did not resemble a floating part in air and that the situation in $\mathrm{SF}_{6}$ could be well recognized: high score for both FLOA-SF 6 and GIS-SPLI (see Section 4.2.12).

Table 10

The recognition rate and centour score for spring in $400 \mathrm{kV}$ GIS compartment at $500 \mathrm{kPa} \mathrm{SF}_{6}$.

\begin{tabular}{|c|c|c|c|}
\hline \hline \multicolumn{2}{|c|}{ Recognition rate } & \multicolumn{2}{|c|}{ Centour score } \\
\hline FLOA-SF & 14 & GIS-Spli & $87 \%$ \\
GIS-Spli & 13 & FLOA-SF & $70 \%$ \\
Others & $\leqslant 10$ & & \\
\hline \hline
\end{tabular}




\subsubsection{CABLE TREEING}

To analyze discharges in a $\mathrm{HV}$ cable, two typical defects were studied: treeing at a sharp electrode and discharges in an electrode bounded cavity. These defects were made artificially. They were placed in the middle of a $1 \mathrm{~m}$ long $6 / 10 \mathrm{kV}$ cable, see Figure 17. To obtain a good screening of the measuring electrode, the electrode was covered with insulating paper and an grounded copper screen.

To obtain treeing discharges, a stainless steel needle with a radius of $50 \mu \mathrm{m}$ was inserted to $1.15 \mathrm{~mm}$ depth into the insulation. The $P E$ cable with the needle was aged $100 \mathrm{~min}$ at $28 \mathrm{kV}$ test voltage. Treeing was initiated from the beginning of the test. Then the cable was subjected to a 5 minutes test at $42 \mathrm{kV}$ test voltage with the results shown in Table 11. It could be concluded that there was a good recognition of treeing, and the indication SHARPDIEL might originate from the stem of the tree.

Table 11.

The recognition rate and centour score for treeing on $6 / 10 \mathrm{kV}$ PE cable.

\begin{tabular}{|c|c|c|c|}
\hline \hline \multicolumn{2}{|c|}{ Recognition rate } & \multicolumn{2}{|c|}{ Centour score } \\
\hline Tree-Cond & 12 & Tree-Cond & $26 \%$ \\
Sharp-Diel & 9 & & \\
Others & $\leqslant 8$ & & \\
\hline
\end{tabular}

\subsubsection{CABLE CAVITY}

To obtain discharges in an electrode-bounded cavity, a cylindrical cavity with a $1 \mathrm{~mm}$ diameter and $1 \mathrm{~mm}$ height was made within the $P E$ insulation, as in Figure 17.

Using a straight detection circuit, the cable was subjected to a $42 \mathrm{kV}$ test voltage throughout $20 \mathrm{~min}$ with the results shown in Table 12. This was interpreted as a cavity adjacent to the conductor; the fact that no square cavity was recognized was not surprising because the set of the studied defects did not include a square cavity at the conductor (see Section 4.1).

\subsubsection{CORONA IN GIS}

In the same $400 \mathrm{kV}$ GIS compartment as before, artificial sources of corona were made by applying aluminum slivers, either to the conductor or to the spacer surface
Table 12.

The recognition rate and centour score for electrode-bounded cavity in $6 / 10 \mathrm{kV}$ PE cable.

\begin{tabular}{|c|c|c|c|}
\hline \multicolumn{2}{|c|}{ Recognition rate } & \multicolumn{2}{|c|}{ Centour score } \\
\hline Flat-Cond & 11 & Flat-Cond & $71 \%$ \\
All other cav & 9 & Others & $\leqslant 2 \%$ \\
Others & $\leqslant 7$ & & \\
\hline \hline
\end{tabular}

near conductor. Both cases gave the same discharge patterns, so that they were classified as one type of defect. The results of several samples were averaged (and their scatter was recorded) as COR-SF 6 . A arbitrary sample was then measured with the following results, see Table 13 . The corona in $500 \mathrm{kPa} \mathrm{SF}_{6}$ was well recognized and showed some similarity to that in ambient air.

Table 13.

The recognition rate and centour score for corona in GIS compartment at $500 \mathrm{kPa} \mathrm{SF}_{6}$.

\begin{tabular}{|c|c|c|c|}
\hline \hline \multicolumn{2}{|c|}{ Recognition rate } & \multicolumn{2}{|c|}{ Centour score } \\
\hline Cor-SF & 13 & Cor-SF & $57 \%$ \\
Cor-Air & 10 & Cor-Air & $9 \%$ \\
Others & $\leqslant 8$ & & \\
\hline \hline
\end{tabular}

4.2.12 COND-PARTICLE GIS-SPACER (I)

A conducting particle at a spacer was simulated by painting a conducting circle of $2 \mathrm{~mm}$ diameter on a 400 $\mathrm{kV}$ spacer. The conducting circle was applied halfway between conductor and ground. A number of samples were prepared in this way and their response was recorded as SPAC-MID. An arbitrary sample was then measured with the results in Table 14. The result of the recognition rate was deemed to be insufficient for recognition and was consequently accepted as no classification. The centour score gave a better recognition of the cause of the discharges, but not convincingly.

Table 14.

The recognition rate and centour score for conducting particle on GIS spacer at $500 \mathrm{kPa} \mathrm{SF}$, applied halfway between conductor and ground.

\begin{tabular}{|c|c|c|c|}
\hline \hline \multicolumn{2}{|c|}{ Recognition rate } & \multicolumn{2}{|c|}{ Centour score } \\
\hline Spac-Mid & 10 & Spac-Mid & $45 \%$ \\
Cor-SF $_{6}$ & 10 & Others & $\leqslant 5 \%$ \\
FLOA-Air & 9 & & \\
Others & 8 & & \\
\hline
\end{tabular}




\section{COND-PARTICLE GIS-SPACER (II)}

In this case the conducting speck of $2 \mathrm{~mm}$ diameter was applied to the spacer near the conductor. The results are shown in Table 15. In contrast to the former case this asymmetrically applied defect can well be classified. The asymmetric discharge pattern of this defect can apparently better be recognized then that of former more symmetric one. It did not resemble any of the other defects, which improves the clarity of the recognition.

Table 15.

The recognition rate and centour score for conducting particle on GIS spacer at $500 \mathrm{kPa} \mathrm{SF}{ }_{\theta}$, applied near conductor.

\begin{tabular}{|c|c|c|c|}
\hline \hline Recognition rate & \multicolumn{2}{|c|}{ Centour score } \\
\hline Spac-Cond & 13 & Spac-Cond & $80 \%$ \\
Others & $\leqslant 8$ & Spac-Mid & $7 \%$ \\
\hline
\end{tabular}

\subsubsection{ALU SLIVER IN GIS}

Aluminum splinters, as they may occur when handling and assembling GIS, were loosely laid at the bottom of several compartments. Their response was recorded as GIS-SPLI. The test of an arbitrary sample is shown in Table 16: The result for recognition rate was deemed insufficient for correct classification. An explanation could be that the analyzing period had been too short as the particle had moved in the electric field and was found, after opening of the compartment, in a field free corner. The centour score did better in this short time span; the sliver was clearly recognized as a floating part in $\mathrm{SF}_{6}$.

Table 16.

The recognition rate and centour score for loosely laid aluminum splinter in GIS compartment at $500 \mathrm{kPa} \mathrm{SF} 6$

\begin{tabular}{|c|c|c|c|}
\hline \hline \multicolumn{2}{|c|}{ Recognition rate } & \multicolumn{2}{|c|}{ Centour score } \\
\hline GIS-Spli & 10 & FLOA-SF 6 & $52 \%$ \\
Cor-Air & 9 & GIS-Spli & $26 \%$ \\
FLOA-Air & 9 & & \\
FLOA-SF $_{6}$ & 7 & & \\
Tree-Cond & 7 & & \\
\hline
\end{tabular}

The results of these tests on full-scale models have been collected in Table 17. This Table shows sixteen industrial objects, together with the expected defects that may cause $\mathrm{PD}$. The results of the tests with recognition rate are shown (highest possible rate is 15 ) as well as those with centour score (highest rate $99 \%$ ). If the classification is correct a verdict + is given, if no classification took place the verdict is $\square$. An incorrect classification would have been indicated by -, but such a classification did not occur. It follows from this Table that quite satisfactory results of classification are obtained. Especially the fact that no incorrect classifications took place is recognized.

A further concentration of the results is presented in Table 18 where the number of good and indistinct classifications are indicated for the two indicators that have been tried out in this study: recognition rate and centour score. It follows from this Table that these two do not differ much in classification. Combination of the two indicators leads to a more attractive score: 13 out of 16 cases are correctly classified, the other 3 represent a situation where no recognition ought to be expected: cable tested at three-phase voltage (see cases $4,5,6$ ).

\section{CONCLUSIONS}

The following conclusions can be drawn:

1. The results on sixteen full scale samples as described here show a good potential for classification of discharging defects in insulation structures.

2. Recognition rate and centour score, as defined in this report, do not differ much in distinctive power. However, the centour score procedure can much be improved, whereas the recognition rate has already been fully developed. The centour score shall be e.g. based on far more observations than were available here. Moreover, the centour score gives a better suppression of irrelevant answers.

3. The development of this technique has now reached a stage that asks for far more experience on the actual use of the system. Three remarks can be made.

Improvements might be obtained by trying out other distributions and operators then described in this paper. However, this is useful only if a good set of well-designed standard defects is developed and tested.

As a consequence of the statement above, cooperation of different users is needed with the aim to develop some level of standardization; especially industrial experience is required. 
Table 17. The results of recognition rate and centour score analysis on 16 industrial objects.

\begin{tabular}{|c|c|c|c|c|c|c|c|c|}
\hline \multirow{2}{*}{\multicolumn{2}{|c|}{ OBIECT }} & \multirow{2}{*}{ EXPECTED DEFECT } & \multicolumn{6}{|c|}{ RESULTS } \\
\hline & & & \multicolumn{2}{|l|}{ RECOGNTION RATE } & \multirow{2}{*}{$\frac{\text { VERDICT }}{+}$} & \multicolumn{2}{|l|}{ CENTOUR SCORE } & \multirow{2}{*}{$\frac{\text { VERDICT }}{\square}$} \\
\hline 1. & $\begin{array}{l}\text { TRANSFORMER } \\
\text { BUSHING (A) }\end{array}$ & $\begin{array}{l}\text { SURFACE AND INTERNAL } \\
\text { DISCHARGES }\end{array}$ & $\begin{array}{l}\text { SUR-AIR } \\
\text { FLAT-DIEL }\end{array}$ & $\begin{array}{l}11 \\
10\end{array}$ & & NO ANSWER & & \\
\hline 2. & $\begin{array}{l}\text { TRANSFORMER } \\
\text { BUSHING (B) }\end{array}$ & INTERNAL DISCHARGES & $\begin{array}{c}\text { FLAT-CONO } \\
\text { EXTRA-FLAT-DIEL }\end{array}$ & $\begin{array}{l}11 \\
10\end{array}$ & + & EXTRA-FLAT-DIEL & $26 \%$ & + \\
\hline 3. & CURRENT TRANSFORMER & FLAT CAVITY & EXTRA-FLAT-DIEL & 11 & + & NO ANSWER & & $\square$ \\
\hline 4. & CABLE PHASE $R$ & NONE & CONFUSING & & $\square$ & NO ANSWER & & $\square$ \\
\hline 5. & CABLE PHASE $s$ & NONE & NO ANSWER & & $\square$ & NO ANSWER & & $\square$ \\
\hline 6. & CABLE PHASE $\mathbf{T}$ & NONE & NO ANSWER & & 口 & NO ANSWER & & $\square$ \\
\hline 7. & 150ky BUSHING $(N)$ & FLAT CAVITY & $\begin{array}{l}\text { FLAT-COND } \\
\text { EXTRA-FLAT-DHEL }\end{array}$ & $\begin{array}{l}12 \\
11\end{array}$ & + & NO ANSWER & & $\square$ \\
\hline 8. & 150kN BUSHING (B) & CAVITY & UNCERTAIN & & 口 & FLAT-DIEL & $40 \%$ & + \\
\hline 9. & GIS-SPACER & CAVITY & CAV-SPAC & 11 & + & CAV-SPAC & $89 \%$ & + \\
\hline 10. & SPRING IN GIS & FLOATING PART & $\begin{array}{l}\text { FLOA-SFG } \\
\text { GIS-SPLI }\end{array}$ & $\begin{array}{l}14 \\
13\end{array}$ & + & $\begin{array}{l}\text { GIS-SPLI } \\
\text { FLOA-SFG }\end{array}$ & $\begin{array}{l}87 \% \\
70 \%\end{array}$ & + \\
\hline 11. & CABLE, TREEING & TREEING & TREE-COND & 12 & + & TREE-COND & $26 \%$ & + \\
\hline 12. & CABLE, CAVITY & CAVITY AT CONDUCTOR & FLAT-COND & 11 & + & FLAT-COND & $71 \%$ & + \\
\hline 13. & NEEDLES IM GIS & CORONA & COR-SFE & 13 & + & COR-SFG & $57 \%$ & + \\
\hline 14. & $\begin{array}{l}\text { CONDUCTING PARTICLE } \\
\text { MIDDLE OF SPACER }\end{array}$ & $\begin{array}{l}\text { ITSELF ANDIOR } \\
\text { SURFACE DISCHARGES }\end{array}$ & CONFUSING & & $\square$ & SPAC-MID & $45 \%$ & + \\
\hline 15. & $\begin{array}{l}\text { CONDUCTING PARTICLE } \\
\text { NEAR CONDUCTOR }\end{array}$ & $\begin{array}{l}\text { ITSELF ANDIOR } \\
\text { SURFACE DISCHARGES }\end{array}$ & SPAC-COND & 13 & + & SPAC-COND & $80 \%$ & + \\
\hline 18. & SPLINTER IN GIS & $\begin{array}{l}\text { SPLINTER OR } \\
\text { FLOATING PART }\end{array}$ & CONFUSING & & $\square$ & FLOA-SFG & 52\% & + \\
\hline
\end{tabular}

Table 18.

A brief survey of verdicts of recognition rates and centour scores as given in Table 17 for industrial models and objects. Number of classifications

\begin{tabular}{|c|c|c|c|}
\hline & Good (+) & Indistinct (D) & Wrong (-) \\
\hline Recognition rate & 10 & 6 & 0 \\
Centour score & 10 & 6 & 0 \\
Combined & 13 & 3 & 0 \\
\hline \hline
\end{tabular}

\section{APPENDIX}

\subsection{CENTOUR SCORE}

The first step in calculating of centour score is made by measuring the distance between the operators of an unknown discharge and the mean values of the operators of the known discharges. A simple example is to classify an unknown measurement into two known defects using one statistical operator. The distance is:

$$
d_{k}^{2}=\frac{\left(u-\mu_{k}\right)^{2}}{\sigma_{k}^{2}} \quad k=1,2
$$

where $u$ is the statistical operator of the unknown discharge, $\mu_{1}$ and $\mu_{2}$ are the means of the same statistical operator for two known defects 1 and $2, \sigma_{1}$ and $\sigma_{2}$ are standard deviations for these two defects. Generally the measure of the distance for the $j$-th unknown measurement $u_{j}$, based on $p$ statistical operators of the $k$-th defect $(k=1,2, \ldots, K)$ is

$$
d_{j k}^{2}=\mathbf{U}_{j k}^{\prime} C_{k}^{-1} \mathbf{U}_{j k}
$$

where the unknown measurement is 


$$
\begin{gathered}
\mathbf{u}_{j}=\left[\begin{array}{c}
u_{j 1} \\
u_{j 2} \\
\vdots \\
u_{j p}
\end{array}\right] \\
\mathbf{U}_{j k}=\left[\begin{array}{c}
u_{j 1}-\mu_{1 k} \\
u_{j 2}-\mu_{2 k} \\
\vdots \\
u_{j p}-\mu_{p k}
\end{array}\right]
\end{gathered}
$$

the covariance matrix

$$
C_{k}=\left[\begin{array}{cccc}
\sigma_{1 k}^{2} & \sigma_{12 k} & \ldots & \sigma_{1 p k} \\
\sigma_{21 k} & \sigma_{2 k}^{2} & \ldots & \sigma_{2 p k} \\
\vdots & \vdots & \ddots & \vdots \\
\sigma_{p 1 k} & \sigma_{p 2 k} & \ldots & \sigma_{p k}^{2}
\end{array}\right]
$$

and $\mathbf{U}_{j k}^{\prime}$ is the transpose of vector $\mathbf{U}_{j k}$. The covariance matrix can be considered as a multidimensional generalization of the one dimensional standard deviation.

However, the parameters like the mean of the statistical operators, the standard deviation, and the covariance matrix are usually unknown in practice. They are estimated from the sampled data. The estimations of the elements of the covariance matrix for $k$-th defect in Equation (9) are

$$
\begin{gathered}
e_{l m}=\frac{\sum_{i=1}^{n_{k}}\left(u_{i l}-\bar{u}_{l}\right)\left(u_{i m}-\bar{u}_{m}\right)}{n_{k}-1} \\
l, m=1,2, \ldots, p
\end{gathered}
$$

where $\bar{u}_{l}$ is the mean value for the $l$-th statistical operator estimated from $n_{k}$ measurements of the $k$-th defect.

If the distribution of $u$ is normal with mean $\mu$ and variance $\sigma^{2}$, Equation (8) has a $\chi^{2}$ distribution with one degree of freedom. This fact was used to create the centour score, a measure of resemblance, see e.g. [14]. The centour score is defined as:

$$
c s=100-P R_{d_{g h(s), p}^{2}}
$$

where $P R$ is the percentile rank of $d_{j k(S)}^{2}$, see Equation (9), in the distribution of $\chi^{2}$ with $p$ degrees of freedom, i.e. if 15 operators are used then $p=15$. The maximum value for $c s$ is 100 , its minimum value is 0 .

\section{REFERENCES}

[1] A. Bargigia, W. Koltunowicz, A. Pigini, "Detection of Partial Discharges in GIS", Conf. Proc. of IEEE/PES Summer Meeting, 1991.
[2] F. H. Kreuger, E. Gulski, W. A. Sonneveld, "Diagnosis in GIS by Statistical Analysis of Discharges", 15/23-04 in Proc. CIGRE Conf., Paris, 1992.

[3] F. H. Kreuger, Partial Discharge Detection in $H V$ Equipment, pp. 126-127, pp. 111-126, pp. 164-170, pp. 111-127, pp. 129-143, Butterworths, London, 1989.

[4] J. H. Reeves, "Location of Partial Discharges in HV Switchgear", Proc. CIRED Conf., Paper 4.12, Brighton, 1981.

[5] F. H. Kreuger, Detection and Location of Discharges, pp. 113-148, Thesis, Delft, 1961.

[6] P. H. F. Morshuis, F. H. Kreuger, "Relation between Time-resolved Discharge Parameters and Aging", Proc. 6th Int. Conf. on Dielectric Materials, Measurements and Applications, Manchester, 1992.

[7] M. Albiez, M. Leijon, "Partial Discharge Measurements in GIS with Electric Field Sensor and Acoustic Sensor", Proc. 7th Int. Symp. HV Eng., Dresden, 1991.

[8] E. Gulski, F. H. Kreuger, "Computer-aided Analysis of Discharge Patterns", J. Phys. D: Appl. Phys. Vol. 23, pp. 1569-1575, 1990.

[9] N. Hozumi, T. Okamoto, T. Imajo, "Discrimination of Partial Discharge Patterns Using Neural Network", IEEE Trans. on Elect. Insul., Vol. 27, pp. 550-556, 1992.

[10] H. Suzuki, T. Endoh, "Pattern Recognition of Partial Discharges in XLPE Cables Using a Neural Network", IEEE Trans. on Elect. Insul., Vol. 27, pp. 543-549, 1992.

[11] E. Gulski, F. H. Kreuger, "Computer-aided Recognition of Discharge Sources", IEEE Trans. on Elect. Insul., Vol. 27, pp. 82-91, 1992.

[12] E. Gulski, Computer-aided Recognition of Partial Discharges Using Statistical Tools, pp. 147-157, pp. 63-141, pp. 159-182, Delft University Press, 1991.

[13] F. H. Kreuger, S. Shihab, "Partial Discharge Measurement of Three-core Belted Power Cables", IEEE Trans. on Power Deliwery, Vol. 4, pp. 927-931, 1989.

[14] R. H. Lindeman, P. F. Merenda, R. Z. Gold, Introduction to Bivariate and Multivariate Analysis, pp. 203-204, Scott, Foresman and Company, 1980.

Manuscript was received on 25 November 1992. 